\title{
Acupuncture for the treatment of severe acute pain in Herpes Zoster: results of a nested, open-label, randomized trial in the VZV Pain Study
}

\author{
Tamara Ursini ${ }^{1 \dagger}$, Monica Tontodonati ${ }^{1 \dagger}$, Lamberto Manzoli ${ }^{2 \dagger}$, Ennio Polilli ${ }^{1}$, Cristina Rebuzzi ${ }^{3}$, Gabriele Congedo $^{4}$, \\ Sonia Di Profio ${ }^{3}$, Patrizia Marani Toro ${ }^{5}$, Augusta Consorte', Giuseppina Placido' ${ }^{1}$, Stefano Laganàn, \\ Claudio D'Amario ${ }^{5}$, Carla Granchelli ${ }^{5}$, Giustino Parruti ${ }^{*}$, Lucio Pippa ${ }^{4}$ and for the VZV Pain Study Group
}

\begin{abstract}
Background: Data on the potential efficacy of acupuncture (AC) in controlling intense or very intense pain in patients with Herpes Zoster $(\mathrm{HZ})$ has not been so far adequately assessed in comparison with standard pharmacological treatment (ST) by a controlled trial design.
\end{abstract}

Methods: Within the VZV Pescara study, pain was assessed in HZ patients on a Visual Analogue Scale (VAS) and by the McGill Pain Questionnaire (MPQ) both at the beginning and at the end of treatment. Response rates, mean changes in pain intensity, differences in total pain burden with an area-under-the-curve (AUC) method over a 1-year follow-up and differences in the incidence of Post-Herpetic Neuralgia (PHN) were evaluated.

Results: One hundred and two patients were randomized to receive either AC $(n=52)$ or $S T(n=50)$ for 4 weeks. Groups were comparable regarding age, sex, pain intensity at presentation and missed antiviral prescription. Both interventions were largely effective. No significant differences were observed in response rates (81.6\% vs $89.2 \%$, $\mathrm{p}=0.8)$, mean reduction of VAS $(4.1+/-2.3$ vs $4.9+/-1.9, \mathrm{p}=0.12)$ and MPQ scores $(1.3+/-0.9$ vs $1.3+/-0.9$, $p=0.9$ ), incidence of PHN after 3 months (48.4\% vs $46.8 \%, p=0.5)$, and mean AUC during follow-up (199+/136 vs $173+/-141, p=0.4$ ). No serious treatment-related adverse event was observed in both groups.

Conclusions: This controlled and randomized trial provides the first evidence of a potential role of AC for the treatment of acute herpetic pain.

Trial registration: ChiCTR-TRC-10001146.

\section{Background}

A significant proportion (18\% to $41 \%)$ of patients suffering with Herpes Zoster (HZ) experience intense or very intense pain at presentation, frequently persisting after the healing of rash [1-4]. Both pain in the acute phase and chronic pain in post-herpetic neuralgia (PHN) may severely impact on quality of life and health care costs, interfering with physical, emotional and social functioning of affected patients [5-7]. Therefore, several investigations

\footnotetext{
* Correspondence: parruti@tin.it

† Contributed equally

${ }^{1}$ Infectious Diseases Unit, Pescara General Hospital, Pescara, Italy
}

Full list of author information is available at the end of the article were carried out to identify effective strategies to control Zoster-related pain [8-11].

Current therapeutic options include the repeated administration of paracetamol and/or other NSAIDs for the immediate relief of pain $[9,10]$, antiviral drugs, which accelerate the resolution of acute pain and may reduce the incidence of PHN [12-14], long-term gabapentinoids and local anaesthesia for selective nerve blockade in patients with intense or very intense pain at presentation [15-21]. Finally, opioid analgesics, including tramadol, possibly combined with other neuroactive agents, such as amitriptyline, have been used in the event of unresponsive pain [22-26]. In the most suffering patients, however,

\section{Biomed Central}

(c) 2011 Ursini et al; licensee BioMed Central Ltd. This is an Open Access article distributed under the terms of the Creative Commons Attribution License (http://creativecommons.org/licenses/by/2.0), which permits unrestricted use, distribution, and reproduction in any medium, provided the original work is properly cited. 
the control of pain is often unsatisfactory despite the administration of complex drug combinations, which also bear the potential of relevant metabolic effects $[11,22]$.

In this context, the evidence that acupuncture may be efficacious in the treatment of neuropathic pain syndromes lead to the hypothesis of a potential beneficial effect of this procedure for acute HZ-related pain [27-29]. Therefore, several studies investigated the impact of acupuncture in patients with intense pain due to $\mathrm{HZ}$ or PHN, with controversial results [13,30-35]. None of them, however, was a randomized controlled trial for acute pain in $\mathrm{HZ}[13,36,37]$.

Here we report on a randomized, controlled trial, comparing the efficacy of acupuncture (AC) and standard pharmacological treatment (ST) in controlling intense or very intense acute pain in patients with $\mathrm{HZ}$.

\section{Methods}

\section{Study design and population}

The present randomized clinical trial was nested within the "VZV Pescara Study", a cohort study aimed at evaluating the intensity of pain at presentation, pain persistence, overall pain burden and relative predictors in $\mathrm{HZ}$ patients [14]. Final approval of the study was granted by the Ethical Committee of the Local Healthcare Agency of Pescara in March, 2006. From May 2006 to April 2008, 41 General Practitioners (GPs) in the district of Pescara, Italy, the Infectious Diseases (ID) Unit, the Dermatology Unit, and Pain Management Clinic (PMC) of the Pescara General Hospital asked all incident cases of $\mathrm{HZ}$ to participate in the cohort study. All data were collected by the Infectious Disease Unit using a specifically created computerized network. All eligible patients granting signed informed consent were followed for 12 months. Patients enrolled in the cohort study with pain classified as intense or very intense on a five-degree semi-quantitative scale (no pain, mild, moderate, intense, very intense) were asked to participate in the present trial. At enrolment, a second specific informed consent was obtained, and the intensity of pain was reassessed using a Visual Analogue Scale (VAS) [38,39]. If the intensity was $\geq 7$ at VAS, participants were randomized to receive either standard pharmacological treatment (ST) or acupuncture (AC). The randomization process was carried out by the Statistical Unit and stratified by gender, age class $(10 \mathrm{y})$ and pain intensity (VAS 7-8, and VAS 9-10). None of the investigators had any role in the allocation of patients.

\section{Intervention}

In the $\mathrm{AC}$ arm, 8 sessions of Traditional Chinese Acupuncture were administered twice weekly by 2 experienced acupuncture physicians, members of the Italian
School of Acupuncture and Traditional Chinese Medicine, Boulogne, Italy. Acupuncture basic points used are shown in Figure 1. In the ST arm, pregabalin was administered to all patients. The initial dose of $75 \mathrm{mg} / \mathrm{d}$ was gradually augmented based on patients' needs (maximum dose: $600 \mathrm{mg} /$ daily, divided in 2 daily doses). In addition to the gabapentinoid, in the ST arm local anaesthesia was administered to all patients using 4-7 $\mathrm{ml}$ of chirocaine $(1.5 \mathrm{mg} / \mathrm{mL})$, either as intermittent peridural neural blockade in those with lumbar or sacral localization, or as intermittent perineural peripheral blockade in the remaining cases. Local anaesthesia was repeated every second day in patients complaining for yet uncontrolled pain, up to 5 administrations. Finally, in the ST arm transdermal buprenorphine $(35-90 \mathrm{mcg} / \mathrm{h})$ or oral oxycodone (50-400 mg daily) were prescribed to patients with very intense or refractory pain. Dosages of opioids were adjusted twice-weekly, in accordance with patients' complaints. Neither pregabalin, local anaesthesia nor opioids were allowed at any time for patients in the AC group; prescription of either drug was considered a protocol violation. For immediate pain relief, however, i.v. or oral paracetamol (250 to $1000 \mathrm{mg}$ in accordance to both body weight and pain intensity) was allowed up to 3 times daily in both study arms. The duration planned for both treatments was 4 weeks.

\section{Outcomes}

The main outcome of the study was the reduction in pain intensity between baseline and the end of the 4-week treatment, as measured by the reduction in the VAS score $[38,39]$. Secondary outcomes included: the reduction in the score of the McGill Pain Questionnaire (MPQ), which was administered by a psychologist for the multidimensional definition of pain in the individual patient [39-41]; the response rate (VAS score decrease by at least 2 points during treatment); the percentage of incident cases of PHN (defined as the presence of pain of any grade 3 months after enrolment data obtained from the nesting cohort study); the total pain burden during the 12-month follow-up of the cohort study; finally, the incidence of treatment-related serious adverse events during treatment (grade 3 or higher according to the WHO scale) [42]. The total pain burden was quantified using an area-under-the-curve (AUC) method [14,43]. In brief, all patients in the cohort study were asked about pain severity at 1, 3, 6 and 12 months after enrolment, using the five-degree semi-quantitative scale described above. To obtain the AUC, measures of pain intensity were combined with pain duration, and each patient's AUC was calculated as the sum of all areas obtained by multiplying the average of 2 consecutive pain scores by the number of days between the scores. 


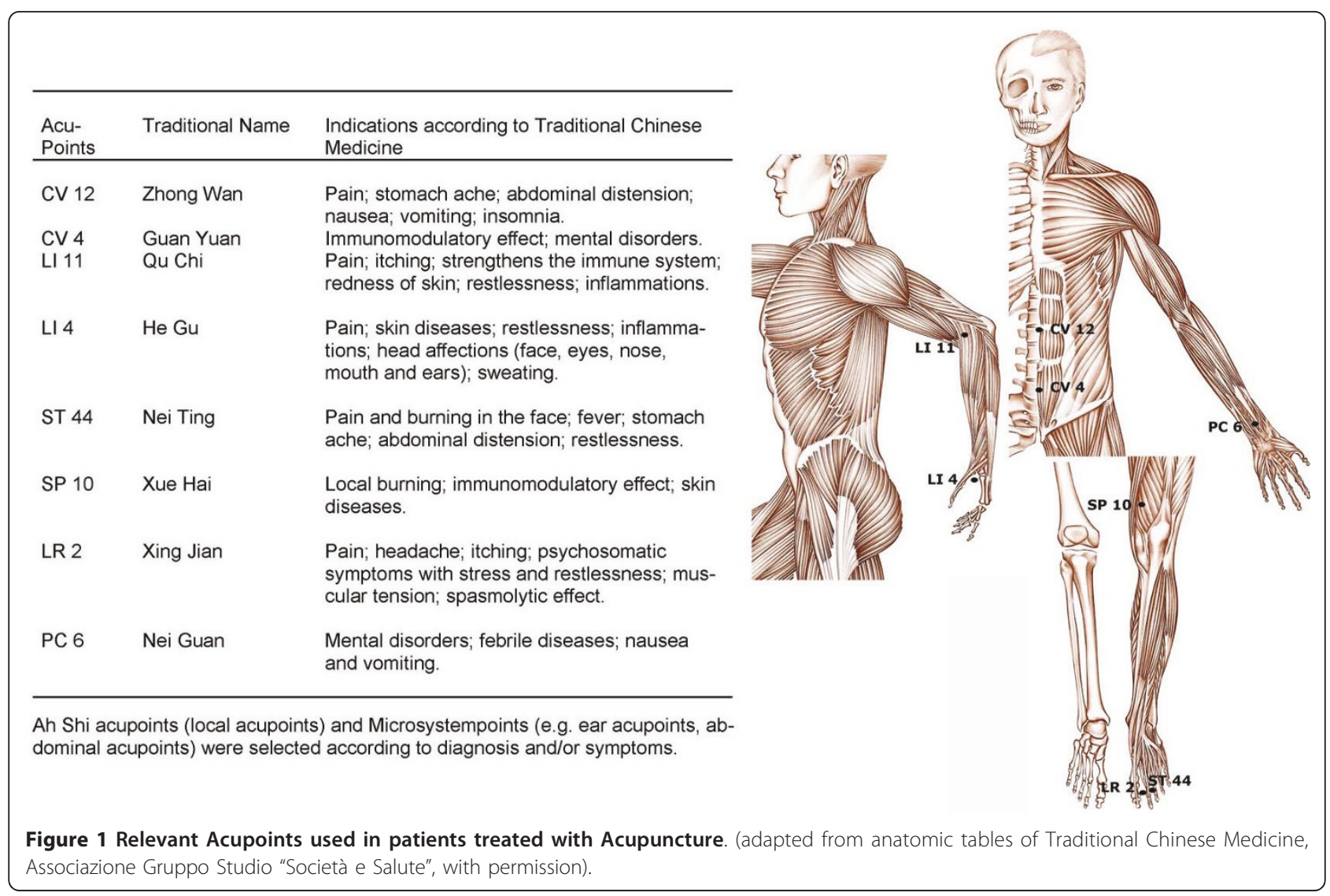

\section{Sample size estimation}

Because of the recent debate on non-inferiority trials [44], the study was conservatively planned with a superiority design. As mentioned above, the main outcome was the difference in the mean change of VAS scores from baseline to the end of the treatment between groups. According to previous studies [30-35] and inclusion criteria, the expected baseline mean VAS score was $8.0 \pm 2.0$ in both groups. The expected mean score at the end of the follow-up was $2.5 \pm 2.0$ in the acupuncture group; $4.0 \pm 2.0$ in the control group, with mean changes from baseline of 5.5 (2.0) and 4.0 (2.0), respectively. Using an unpaired t-test, and assuming an alphaerror $=0.05$ and an expected withdrawal/dropout rate of $20 \%$, a minimum of 34 subjects per group were requested to achieve a $80 \%$ statistical power.

\section{Data analysis}

Kruskal-Wallis test was used to compare VAS, McGill and AUC mean scores across groups at each time point, as well as the mean change in each score during the follow-up. Chi-squared test was used to compare the VAS response rate and the prevalence of PHN between groups. Within each group, the differences in VAS and McGill scores between baseline and the end of the 4-week treatment were evaluated using paired t-test and confirmed through the Wilcoxon matched-pairs signed ranks test. A two-tailed p-value of 0.05 was considered significant for all analyses, which were carried out using Stata 10.1 (Stata Corp., College Station, TX, 2007).

\section{Results}

\section{Characteristics of the sample}

During the 2 years of enrolment in the VZV Pescara cohort study, 451 patients were clinically and/or microbiologically diagnosed as $\mathrm{HZ}$ [14]. Of them, 129 reported intense or very intense pain at presentation and were thus eligible for the present trial. Twentyseven patients (21\%) refused to participate, and 102 patients were randomized to receive either acupuncture (AC, $\mathrm{n}=52$ ) or standard therapy (ST, $\mathrm{n}=50$ ) (Figure 2). Many of the randomized patients, however, did not receive the allocated intervention, because of rapid pain quenching after enrolment $(n=13$ in $A C, n=14$ in ST), or for consent withdrawal after randomization $(n=1$ in each group). Finally, $1 \mathrm{AC}$ and $2 \mathrm{ST}$ patients were lost to follow-up, and 2 patients in each group underwent protocol violations (Figure 2). The final analyses were thus based upon 34 patients in the AC group and 32 patients in the ST group (Figure 2). 


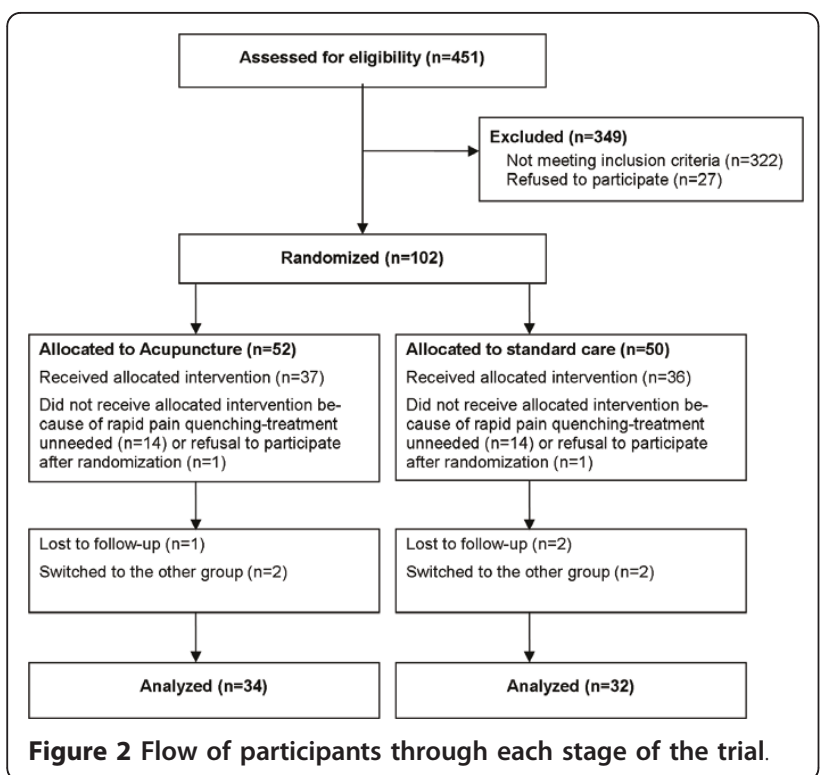

In the initial sample of 102 randomized patients, no differences between groups were observed in mean age $(63.2 \pm 16.1 \mathrm{y}$ in $\mathrm{ST} ; 64.2 \pm 14.7 \mathrm{y}$ in $\mathrm{AC})$, male gender (30.0\% in ST and $35.5 \%$, in AC), pain intensity at presentation (21.8\% with very intense pain in ST; $23.6 \%$ in $\mathrm{AC})$ and missed antiviral prescription (10.0\% in ST and $15.4 \%$ in AC). Similarly, as shown in Table 1, demographic and clinical characteristics of the 66 patients entering the final analyses were well balanced between groups. Finally, no differences were observed between the 66 patients in the final sample and the 27 patients refusing to participate (mean age $64.2 \pm 16.0 \mathrm{y}$, males $18.5 \%, 17.4 \%$ with very intense pain). By contrast, and expectedly, the 28 patients excluded after randomization because of rapid pain reduction were significantly younger (mean age $56.6 \pm 19.8 \mathrm{y}, \mathrm{p}<0.01$ ) and with less severe pain at presentation $(7.1 \%$ with very intense pain, $\mathrm{p}=0.04$ ).

\section{Efficacy of acupuncture and standard analgesic therapy}

As shown in Table 2, the 2 groups were also similar at baseline as to the mean VAS and McGill scores ( $p=$ $0.6, p=0.8$, respectively). Both interventions were largely effective: the mean percentage of VAS score reduction from baseline to week 4 was of $51 \%$ in the ST group (mean reduction in VAS score $=4.12 \pm 2.3$ ), and $62 \%$ in the AC group (mean reduction in VAS score = $4.85 \pm 1.9$ ); the mean percentage of McGill score reduction was $57 \%$ and $56 \%$, respectively. Indeed, a highly significant improvement from baseline to the end of the follow-up was observed in each group for both pain scores, and correspondent $\mathrm{p}$-values were thus not reported in the table (all $\mathrm{p}<0.001$ ).
Table 1 Demographic and clinical characteristics of treated patients, by group

\begin{tabular}{|c|c|c|c|}
\hline Characteristics & $\begin{array}{l}\text { Standard } \\
\text { Therapy } \\
(\mathrm{n}=32)\end{array}$ & $\begin{array}{l}\text { Acupuncture } \\
(n=34)\end{array}$ & $\mathrm{p}^{*}$ \\
\hline Male gender, \% & 40.6 & 32.3 & 0.5 \\
\hline Mean age in years (SD) & $65.5(12.8)$ & $67.1(12.8)$ & 0.6 \\
\hline Current smoking, \% & 37.5 & 38.1 & 0.8 \\
\hline $\begin{array}{l}\text { High-school or higher educational } \\
\text { level, \% }\end{array}$ & 28.1 & 35.3 & 0.5 \\
\hline Depression (clinical diagnosis), \% & 0.0 & 5.9 & 0.2 \\
\hline HIV-positive, \% & 0.0 & 0.0 & 0.9 \\
\hline Missed antiviral prescription, \% & 15.6 & 17.6 & 0.8 \\
\hline $\begin{array}{l}\text { Very intense pain at } \\
\text { presentation, } \%\end{array}$ & 30.0 & 29.0 & 0.9 \\
\hline Vesicles (>50), \% & 35.0 & 48.4 & 0.3 \\
\hline $\begin{array}{l}\text { Trauma at the site of VZV up to } 6 \\
m \text { before onset, } \%\end{array}$ & 28.1 & 39.4 & 0.3 \\
\hline $\begin{array}{l}\text { Surgical intervention at the site of } \\
\text { rash up to } 6 \text { months before } \\
\text { onset, } \%\end{array}$ & 59.4 & 55.9 & 0.8 \\
\hline \multicolumn{4}{|l|}{ Site of lesions } \\
\hline Facial & 9.4 & 23.5 & 0.12 \\
\hline Cervical & 6.3 & 8.8 & 0.7 \\
\hline Thoracic & 53.1 & 44.1 & 0.5 \\
\hline Lumbar & 31.2 & 23.5 & 0.8 \\
\hline \multicolumn{4}{|l|}{ Extension of lesions } \\
\hline Subdermatomerical & 28.1 & 26.5 & 0.9 \\
\hline Dermatomerical & 59.4 & 67.6 & 0.5 \\
\hline Multidermatomerical & 12.5 & 5.9 & 0.3 \\
\hline \multicolumn{4}{|l|}{ Antiviral therapy } \\
\hline Acyclovir & 40.6 & 32.4 & 0.5 \\
\hline Famcyclovir & 0 & 5.9 & 0.2 \\
\hline Valacyclovir & 31.3 & 29.4 & 0.9 \\
\hline Brivudin & 9.4 & 11.8 & 0.8 \\
\hline Other antiviral & 3.1 & 2.9 & 0.9 \\
\hline Missed antiviral prescription & 15.6 & 17.6 & 0.8 \\
\hline
\end{tabular}

* Fisher's exact test for categorical variables, t-test for continuous variables (age).

\section{Comparison between acupuncture and standard analgesic therapy}

No significant differences were observed between the 2 therapeutic approaches in any of the outcomes under consideration (Table 2). Neither the mean reduction in VAS score $(p=0.12)$ or in McGill score $(p=0.9)$, nor the response rate $(\mathrm{p}=0.8)$, nor the incidence of PHN after 3 months $(\mathrm{p}=0.5)$, nor the mean AUC (total pain burden) during follow-up ( $p=0.4)$ were significantly different across groups.

As to safety, no serious adverse events (grade 3-4 according to WHO safety scale) related to both treatments were observed in the 2 groups. In addition, none of the patients were hospitalized or died during the 4 week treatment. Finally, none of them discontinued 
Table 2 Comparison of the outcomes of treatments under evaluation

\begin{tabular}{|c|c|c|c|}
\hline Outcomes & $\begin{array}{l}\text { Standard } \\
\text { Therapy } \\
(\mathrm{n}=32)\end{array}$ & $\begin{array}{l}\text { Acupuncture } \\
(n=34)\end{array}$ & $\mathrm{p}^{*}$ \\
\hline \multicolumn{4}{|l|}{ Primary outcomes } \\
\hline \multicolumn{4}{|l|}{ VAS } \\
\hline $\begin{array}{l}\text { Mean VAS score at baseline } \\
\text { (SD) }\end{array}$ & $8.02(1.69)$ & $7.81(1.48)$ & 0.6 \\
\hline $\begin{array}{l}\text { Mean VAS score after therapy } \\
\text { (SD) }\end{array}$ & $3.89(2.38)$ & $2.96(1.84)$ & 0.08 \\
\hline $\begin{array}{l}\text { Mean change in VAS score } \\
\text { (SD) }\end{array}$ & $4.12(2.29)$ & $4.85(1.87)$ & 0.12 \\
\hline $\begin{array}{l}\text { Response rate ( }>=2 \text { VAS units } \\
\text { decrease), } \%\end{array}$ & 81.6 & 89.2 & 0.8 \\
\hline \multicolumn{4}{|l|}{ Secondary outcomes } \\
\hline \multicolumn{4}{|l|}{ McGill score } \\
\hline $\begin{array}{l}\text { Mean McGill score at } \\
\text { baseline (SD) }\end{array}$ & $2.32(1.05)$ & $2.38(1.12)$ & 0.8 \\
\hline $\begin{array}{l}\text { Mean McGill score after } \\
\text { therapy (SD) }\end{array}$ & $0.99(0.69)$ & $0.99(0.73)$ & 0.9 \\
\hline $\begin{array}{l}\text { Mean change in McGill score } \\
\text { (SD) }\end{array}$ & $1.32(0.85)$ & $1.33(0.88)$ & 0.9 \\
\hline $\begin{array}{l}\text { Post-herpetic neuralgia at } \\
3 \text { months, \% }\end{array}$ & 48.4 & 46.8 & 0.9 \\
\hline $\begin{array}{l}\text { Post-herpetic neuralgia at } \\
6 \text { months, } \%\end{array}$ & 33.3 & 29.0 & 0.7 \\
\hline $\begin{array}{l}\text { Post-herpetic neuralgia at } \\
12 \text { months, } \%\end{array}$ & 10.3 & 3.6 & 0.3 \\
\hline $\begin{array}{l}\text { Mean AUC during follow-up } \\
\text { (SD) }\end{array}$ & 199(136) & 173(141) & 0.5 \\
\hline
\end{tabular}

VAS $=$ Visual Analogical Scale. AUC = Area under the curve (see text for details).

* Kruskal-Wallis test was used to compare VAS, McGill and AUC mean scores across groups at each time point, as well as the mean change in each score during the follow-up. Chi-squared test was used to compare the VAS response rate and the prevalence of PHN at each time point across groups. A paired ttest was used to compare baseline vs end of therapy mean values of VAS and McGill scores, within each group. All such differences were highly significant $(p<0.001)$ and were thus omitted in the table to avoid redundancy.

treatment due to drug-related complications or procedure-related discomfort.

\section{Discussion}

Lack of proper efficacy evaluations, adequate statistical power and rational design of the previous studies assessing the role of Acupuncture for Zoster related acute pain is acknowledged [36,37]. Coghlan reported in 1992 the treatment of a small case series of patients with pain caused either by acute $\mathrm{HZ}$ or by $\mathrm{PHN}$, including 4 patients each. Electro-acupuncture alone was used and reported as generally effective, endorsing the opportunity for an exploratory trial [30]. More recently, Ni et al. reported the treatment of 48 cases of $\mathrm{HZ}$ by nerve stem puncturing. Among these, all of the 16 cases treated within 1 week from pain onset were reported as cured, in comparison with only 5 (15.6\%) among the 32 cases whose pain lasted over 1 week before treatment [33].
This study was based on a consecutive case series and lacked of any control arm [33]. He et al. [32] described 60 cases of senile $\mathrm{HZ}$ treated by encircled acupuncture plus valacyclovir (300 mg twice daily orally for 10 days) versus valacyclovir only. The authors report that patients were divided into 2 well balanced treatment groups, not mentioning any randomization process; no alternative analgesic treatment was administered to the control group [32]. The only significantly different outcome between groups was the duration of acute pain (3.8 days for combined treatment vs 5.5 days for valacyclovir only); furthermore, a lower incidence of pain persistence during follow-up was reported for patients undergoing combined treatment (26.7 vs 53.3\%), although no definition was provided neither for PHN nor for the duration of follow-up [32]. Therefore, to our knowledge, this is the first randomized clinical trial assessing the efficacy of acupuncture for the control of HZrelated intense or very intense acute pain as well as for the prevention of PHN during follow-up [30,32,33,36,37]. We found that both AC and ST, associated with the prescription of antivirals, were efficacious in controlling intense or very intense pain. Importantly, the degree of pain control provided by AC was not significantly different from that of ST.

Pain intensity was evaluated by the most frequently used methods in VZV-related pain studies: VAS, to obtain an easy quantification of pain intensity [38,39]; McGill Pain Questionnaire to qualifying pain [39-41]. We found no significant difference both in VAS and McGill scores after 4 weeks of treatment between AC and ST. Since pain intensity at rash onset is widely reported as the best predictor of PHN [6,45-48], having selected for patients with intense or very intense pain we also evaluated the incidence of PHN at 3, 6 and 12 months after rash onset, as well as the total pain burden during follow-up in the 2 study arms. Under the assumption that acupuncture may have an immune modulating activity [49-52], evaluating these endpoint might have revealed an ability of this medical tool to influence the rate of pain persistence and relapses. The incidence of PHN at 3, 6 and 12 months, as well as the mean AUC were overlapping in the 2 arms (Table 2). The limited dimensions of our population do not allow, however, to conclusively exclude, although unlikely, this hypothesis.

It should be noted that the stratification for pain resulted in a perfect match of patients with very intense pain at presentation, which could have otherwise remarkably influenced the validity of our results for all endpoints. Furthermore, the percentage of patients which did not receive antiviral therapy was identical in the 2 arms (15.6\% and $17.6 \%$, respectively), protecting our trial from another possible confounding factor, that 
is a difference in potential control of acute $\mathrm{HZ}$ pain by antiviral therapy between groups $[1,53]$.

This study has some limitations, however, that must be considered in interpreting results. First, we decided to measure pain intensity both by VAS and McGill scales at study entrance and after 4 weeks of treatment, that is when the investigator felt that his intervention for the control of acute pain was complete. Clearly, it would have been interesting to measure ongoing pain control at intermediate time points, to better appreciate minor differences between the investigational arms. This was not feasible, however, due to study budget constraints; in any case, most of the other investigations assessing the efficacy of experimental treatments for pain control were built with very similar or identical designs $[54,55]$.

Second, our trial was based upon a relatively small sample of treated patients $(\mathrm{n}=66)$. However, 41 GPs and 3 hospital units were committed to recruit $\mathrm{HZ}$ patients for 2 years, and more than $400 \mathrm{HZ}$ patients had to be enrolled to identify 129 patients with intense or very intense pain at presentation (those with the highest need of improvements in pain control). In addition, a relatively large number of the eligible patients $(n=27)$ refused to enter the trial. However, this was probably unavoidable because of distrust or fear of an unusual technique such as acupuncture. Notably, no differences in age, gender and pain intensity were observed between these patients and those included in our analyses. Finally, 28 patients were excluded immediately after randomization because of rapid pain reduction. However, it would clearly have been unethical to enforce these patients in a strong analgesic therapy as well as acupuncture. Notably, and expectedly, the latter patients were younger and had very intense pain in only 2 cases. This is the reason why it would have had very little sense to use an intention-to-treat analysis, which is usually the gold standard analysis for RCTs [56], in this case. In other terms, the 28 patients with rapid pain reduction represent a separate group of patients, not needing long term analgesic therapy; they therefore may not carry the potential for selection bias. As a final remark on sample size, it should be noted that the results of the 2 interventions were very similar and, using a one-tailed non-inferiority approach, the statistical power of our analysis is acceptable for all outcomes, ranging from a minimum of $81 \%$ for the change in VAS score, up to $86 \%$ for the change in McGill score.

A third limitation is represented by the lack of both a control arm with short acting analgesics only, and a control arm with mock acupuncture [57-59]. This was beyond our scope because of study budget constraints. However, as the access to alternative drugs and complementary medicine techniques for acute pain control is on the rise in our area and elsewhere in the world, we felt that the design of this nested trial, investigating "real life" differences in therapeutic potential between ST and $\mathrm{AC}$ as presently used in severely ill $\mathrm{HZ}$ patients, might still add to the knowledge on the analgesic efficacy of acupuncture. Indeed, proper stratification of patients between arms rather than blinding might have influenced the assessment of the efficacy of either intervention, that is taking into account - when distributing patients between arms - the main factors that may influence the efficacy of either intervention, such as age, pain intensity and missed antiviral prescription. These variables were indeed well-matched in our study population. A direct comparison between ST and AC for acute pain in $\mathrm{HZ}$ is the object of another three-armed, partially blinded randomized trial, known as ACUZoster, whose design was recently published and which is still ongoing [60].

\section{Conclusions}

With these caveats, our study provides the first evidence from a randomized controlled design of a potential role of acupuncture in the treatment of acute herpetic pain. Patients with intense or very intense pain at presentation showed a significant and similar degree of pain relief using acupuncture and standard pharmacological therapy. Also, no differences between treatments were observed in the incidence of severe adverse events. Given that patients treated with acupuncture carry a lower risk of cumulative drug toxicity, if these findings will be confirmed by the ensuing ACUZoster trial and/ or by other investigations, acupuncture might be appropriately considered among the available therapeutic options for the control of severe acute HZ related pain.

\section{Abbreviations}

AC: Acupuncture; ST: Standard Pharmacological Treatment; VAS: Visual Analogue Scale; MPQ: McGill Pain Questionnaire; AUC: Area Under the Curve; PHN: Post Herpetic Neuralgia; HZ: Herpes Zoster; GPs: General Practitioners; ID: Infectious Disease; PMC: Pain Management Clinic.

\section{Acknowledgements}

This investigation was funded by the Fondazione Onlus Camillo de Lellis per I'Innovazione e la Ricerca in Medicina, Pescara, Italy, and by the Ministry of Health of the Abruzzo Region (protocol n.1269, 30/Nov/2004). Both Institutions granted the unusual opportunity of carrying out a study design completely independent of the influence of pharmaceutical companies; this was motivated by the strive to improve daily assistance to $\mathrm{HZ}$ patients and their acute pain. A permanent network was established in our area as a consequence of the study design. We are heavily indebted to Mr. Massimo Franciotti, who assisted us in most of secretarial work throughout the study, together with Mrs. Bianca Zappalorto. Their help was invaluable in tracking patients beyond outpatient visits. We are also indebted to Mrs. Loredana Puglielli, Mrs. Angela Pisciella, and to Mr. Vincenzo Massei, for their precious and constant help with $\mathrm{HZ}$ outpatients, and to Mrs. Rosanna D'Amico, for her precious assistance to patients in the PMC clinic. We are grateful to many other nurses, colleagues, students and young Medical Doctors in Pescara General Hospital, who provided us invaluable help and assistance in caring for $\mathrm{HZ}$ patients. 
The VZV Pain Study Group is composed by the following Medical Doctors in the Pescara Health District: Luana Cosentino, Luigi Clerico, Assunta Manna, Elena Mazzotta, Federica Sozio, Adriana Agostinone, Francesco Di Masi, Carlo Carunchio, Domenico D'Antonio, Valter Armellani, Silvio Basile, Mariapia Blasetti, Loredana Marano, Massimo Calisi, Enzo Di Benedetto, Sergio Finucci, Luciano Cervone, Pasquale Cordoma, Camilla Palombo, Lucio Ciammaricone, Gina Ciccarelli, Moreno D’Emilio, Giuseppe De Filippo, Dino De Sanctis, Enzo De Sanctis, Gianni Di Fermo, Teresa Galante, Alvaro Mazzocchetti, Fabio Panzieri, Sante Pardo, Stefania Plessi, Paolo Primavera, Carlo Santuccione, Renato Seller, Emidio Spazzafumo, Maurizio Todisco, Antonella Legge, Patrizia Rodriguez, Marisa Diodati, Attilio Cupaiolo, Luciana Alterio, Giulio Calella.

\section{Author details}

${ }^{1}$ Infectious Diseases Unit, Pescara General Hospital, Pescara, Italy. ${ }^{2}$ Section of Epidemiology and Public Health, University of Chieti, Italy. ${ }^{3}$ Pain

Management Clinic, Pescara General Hospital, Pescara, Italy. ${ }^{4}$ Fondazione Onlus Camillo de Lellis per I'Innovazione e la Ricerca in Medicina, Pescara, Italy. ${ }^{5}$ Pescara Health District, Pescara, Italy.

\section{Authors' contributions}

GP, LP, TU, CR, CG CDA and MT conceived and coordinated the study; GP, $L M, L P, C D A$ and $C G$ designed the trial. $L M, L P, G P, E P, A C, C D A$ and $C G$ interpreted and discussed the results of the trial; LM, GP and EP performed the statistical analyses; CR prescribed and performed the standard pharmacological analgesic treatments; LP and GC performed acupuncture treatments; SDP, AC and GPI administered and corrected McGill Pain questionnaire; PMT and SL randomized and tracked all patients; TU, GP, MT, AC and GPI followed the clinical status of patients under observation; SL, CG and PMT cared for the online database; GP, TU, MT, EP, LM, CG and CDA wrote and revised the manuscript. All authors read and approved the final manuscript.

\section{Competing interests}

The authors declare that they have no competing interests.

Received: 20 December 2010 Accepted: 5 June 2011

Published: 5 June 2011

\section{References}

1. Dworkin RH, Portenoy RK: Pain and its persistence in herpes zoster. Pain 1996, 67:241-251.

2. Hope-Simpson RE: The Nature of Herpes Zoster: A Long-Term Study and a New Hypothesis. Proc $R$ Soc Med 1965, 58:9-20.

3. Johnson RW: The future of predictors, prevention, and therapy in postherpetic neuralgia. Neurology 1995, 45(12 Suppl 8):S70-72.

4. Watson CP, Oaklander AL: Postherpetic neuralgia. Pain Pract 2002, 2:295-307.

5. Dworkin RH, Gnann JW Jr, Oaklander AL, Raja SN, Schmader KE, Whitley RJ: Diagnosis and assessment of pain associated with herpes zoster and postherpetic neuralgia. J Pain 2008, 9(1 Suppl 1):S37-44.

6. Dworkin RH, White R, O'Connor AB, Baser O, Hawkins K: Healthcare costs of acute and chronic pain associated with a diagnosis of herpes zoster. $J$ Am Geriatr Soc 2007, 55:1168-1175.

7. Katz J, Cooper EM, Walther RR, Sweeney EW, Dworkin RH: Acute pain in herpes zoster and its impact on health-related quality of life. Clin Infect Dis 2004, 39:342-348.

8. Boureau F, Legallicier P, Kabir-Ahmadi M: Tramadol in post-herpetic neuralgia: a randomized, double-blind, placebo-controlled trial. Pain 2003, 104:323-331.

9. Dworkin RH, Johnson RW, Breuer J, Gnann JW, Levin MJ, Backonja M, Betts RF, Gershon AA, Haanpaa ML, McKendrick MW, et al: Recommendations for the management of herpes zoster. Clin Infect Dis 2007, 44(Suppl 1):S1-26.

10. Mustafa MB, Arduino PG, Porter SR: Varicella zoster virus: review of its management. J Oral Pathol Med 2009, 38(9):673-688.

11. Whitley RJ, Volpi A, McKendrick M, Wijck A, Oaklander AL: Management of herpes zoster and post-herpetic neuralgia now and in the future. J Clin Virol 2010, 48(Suppl 1):S20-28.

12. Gnann JW Jr, Whitley RJ: Clinical practice. Herpes zoster. N Eng/ J Med 2002, 347:340-346.
13. Hui F, Cheng A, Chiu M, Vayda E: Integrative approach to the treatment of postherpetic neuralgia: a case series. Altern Med Rev 1999, 4:429-435.

14. Parruti G, Tontodonati M, Rebuzzi C, Polilli E, Sozio F, Consorte A, Agostinone A, Di Masi F, Congedo G, D'Antonio D, et al: Predictors of pain intensity and persistence in a prospective Italian cohort of patients with herpes zoster: relevance of smoking, trauma and antiviral therapy. BMC Med 2010, 8:58.

15. Dubinsky RM, Kabbani H, El-Chami Z, Boutwell C, Ali H: Practice parameter: treatment of postherpetic neuralgia: an evidence-based report of the Quality Standards Subcommittee of the American Academy of Neurology. Neurology 2004, 63:959-965.

16. Fink K, Dooley DJ, Meder WP, Suman-Chauhan N, Duffy S, Clusmann H, Gothert M: Inhibition of neuronal $\mathrm{Ca}(2+)$ influx by gabapentin and pregabalin in the human neocortex. Neuropharmacology 2002, 42:229-236.

17. Johnson RPD: Improving the management of varicella, herpes zoster and zoster-associated pain: recommendations from the IHMF Management Stategies Workshop [online].[http://www.ihmf.org/library/monograph/ m_11.pdf].

18. Johnson RW: Herpes zoster in the immunocompetent patient: management of post-herpetic neuralgia. Herpes 2003, 10:38-45.

19. Schmader K: Herpes zoster in older adults. Clin Infect Dis 2001, 32:1481-1486

20. Roxas M: Herpes zoster and postherpetic neuralgia: diagnosis and therapeutic considerations. Altern Med Rev 2006, 11:102-113.

21. Wu CL, Marsh A, Dworkin RH: The role of sympathetic nerve blocks in herpes zoster and postherpetic neuralgia. Pain 2000, 87:121-129.

22. Attal N, Cruccu G, Baron R, Haanpaa M, Hansson P, Jensen TS, Nurmikko T: EFNS guidelines on the pharmacological treatment of neuropathic pain: 2010 revision. Eur J Neurol 2010, 17:1113-e1188.

23. Christo PJ, Hobelmann G, Maine DN: Post-herpetic neuralgia in older adults: evidence-based approaches to clinical management. Drugs Aging 2007, 24:1-19.

24. Niv D, Maltsman-Tseikhin A: Postherpetic neuralgia: the never-ending challenge. Pain Pract 2005, 5:327-340.

25. Hempenstall K, Nurmikko TJ, Johnson RW, A'Hern RP, Rice AS: Analgesic therapy in postherpetic neuralgia: a quantitative systematic review. PLoS Med 2005, 2:e164.

26. Raja SN, Haythornthwaite JA, Pappagallo M, Clark MR, Travison TG Sabeen S, Royall RM, Max MB: Opioids versus antidepressants in postherpetic neuralgia: a randomized, placebo-controlled trial. Neurology 2002, 59:1015-1021.

27. Galantino ML, Eke-Okoro ST, Findley TW, Condoluci D: Use of noninvasive electroacupuncture for the treatment of HIV-related peripheral neuropathy: a pilot study. J Altern Complement Med 1999, 5:135-142.

28. Shlay JC, Chaloner K, Max MB, Flaws B, Reichelderfer P, Wentworth D, Hillman S, Brizz B, Cohn DL: Acupuncture and amitriptyline for pain due to HIV-related peripheral neuropathy: a randomized controlled trial. Terry Beirn Community Programs for Clinical Research on AIDS. JAMA 1998, 280:1590-1595.

29. Spacek A, Hanl G, Groiss O, Koinig H, Kress HG: Acupuncture and ganglionic local opioid analgesia in trigeminal neuralgia. Wien Med Wochenschr 1998, 148:447-449.

30. Coghlan CJ: Herpes zoster treated by acupuncture. Cent Afr J Med 1992 38:466-467.

31. Lewith GT, Field J, Machin D: Acupuncture compared with placebo in post-herpetic pain. Pain 1983, 17:361-368.

32. He $Y$, Fang R: Treatment of 60 cases of senile herpes zoster by encircled acupuncture plus valaciclovir. J Acupunct Tuina Sci 2007, 5:171-173.

33. Ni X: Treatment of 48 cases of herpes zoster by puncturing nerve stem. J Acupunct Tuina Sci 2008, 6:368-369.

34. Rutgers MJ, van Romunde LKJ, Osman PO: A small randomized comparative trial of acupuncture versus transcutaneous electrical neurostimulation in postherpetic neuralgia. Pain Clin 1988, 2:87-89

35. Wang S: Treatment of 30 cases of post-herpetic neuralgia by acupuncture combined with point injection. J Acupunct Tuina Sci 2008, 6:182-183.

36. Peng WN, Liu ZS, Deng YH, Mao M, Yu JN, Du Y: Evaluation of literature quality of acupuncture for treatment of herpes zoster and approach to the laws of treatment. Chinese acupuncture \& moxibustion 2008, 28:147-150. 
37. Yu XM, Zhu GM, Chen YL, Fang M, Chen YN: Systematic assessment of acupuncture for treatment of herpes zoster in domestic clinical studies. Chinese acupuncture \& moxibustion 2007, 27:536-540.

38. Hao S, Tian B, Wang L: A primary evaluation of VAS for use in clinical experimentral pain assessment. Zhongguo Yi Xue Ke Yuan Xue Bao 1994, 16:397-399.

39. Thyregod HG, Rowbotham MC, Peters M, Possehn J, Berro M, Petersen KL: Natural history of pain following herpes zoster. Pain 2007, 128:148-156.

40. Melzack R, Torgerson WS: On the language of pain. Anesthesiology 1971, 34:50-59.

41. Melzack R: The McGill pain questionnaire: from description to measurement. Anesthesiology 2005, 103:199-202.

42. Cancer Therapy Evaluation Program, Common Terminology Criteria for Adverse Events, Version 3.0. 2003 [http://ctep.cancer.gov], Publish Date: August 2009. Last accessed Aug 23, 2010.

43. Coplan PM, Schmader K, Nikas A, Chan IS, Choo P, Levin MJ, Johnson G, Bauer M, Williams HM, Kaplan KM, et al: Development of a measure of the burden of pain due to herpes zoster and postherpetic neuralgia for prevention trials: adaptation of the brief pain inventory. J Pain 2004, 5:344-356.

44. Garattini S, Bertele V: Non-inferiority trials are unethical because they disregard patients' interests. Lancet 2007, 370(9602):1875-1877.

45. Jung BF, Johnson RW, Griffin DR, Dworkin RH: Risk factors for postherpetic neuralgia in patients with herpes zoster. Neurology 2004, 62:1545-1551.

46. Opstelten W, Zuithoff NP, van Essen GA, van Loon AM, van Wijck AJ, Kalkman CJ, Verheij TJ, Moons KG: Predicting postherpetic neuralgia in elderly primary care patients with herpes zoster: prospective prognostic study. Pain 2007, 132(Suppl 1):S52-59.

47. Scott FT, Leedham-Green ME, Barrett-Muir WY, Hawrami K, Gallagher WJ, Johnson R, Breuer J: A study of shingles and the development of postherpetic neuralgia in East London. J Med Virol 2003, 70(Suppl 1): S24-30.

48. Whitley RJ, Weiss HL, Soong SJ, Gnann JW: Herpes zoster: risk categories for persistent pain. J Infect Dis 1999, 179:9-15

49. Bresler DE, Kroening RJ: Three essential factors in effective acupunture therapy. Am J Chin Med (Gard City N Y) 1976, 4:81-86.

50. Quirico PE LG, Allais G: L'effetto immunomodulatore dell'agopuntura. $G$ Ital Riflessot Agopunt 1996, 8:175-179.

51. Yan WK, Wang JH, Chang QQ: Effect of leu-enkephalin in striatum on modulating cellular immune during electropuncture. Sheng Li Xue BaO 1991, 43:451-456.

52. Yu Y, Kasahara T, Sato T, Guo SY, Liu Y, Asano K, Hisamitsu T: Enhancement of splenic interferon-gamma, interleukin-2, and NK cytotoxicity by S36 acupoint acupuncture in F344 rats. Jpn J Physiol 1997, 47:173-178.

53. Helgason S, Petursson G, Gudmundsson S, Sigurdsson JA: Prevalence of postherpetic neuralgia after a first episode of herpes zoster: prospective study with long term follow up. BMJ 2000, 321:794-796.

54. Zheng Z, Guo RJ, Helme RD, Muir A, Da Costa C, Xue CC: The effect of electroacupuncture on opioid-like medication consumption by chronic pain patients: a pilot randomized controlled clinical trial. Eur J Pain 2008, 12:671-676.

55. Zin CS, Nissen LM, O'Callaghan JP, Duffull SB, Smith MT, Moore BJ: A randomized, controlled trial of oxycodone versus placebo in patients with postherpetic neuralgia and painful diabetic neuropathy treated with pregabalin. J Pain 2010, 11:462-471.

56. Schulz KF, Altman DG, Moher D: CONSORT 2010 Statement: updated guidelines for reporting parallel group randomised trials. Trials 2010, 11:32.

57. Linde $K$, Allais G, Brinkhaus B, Manheimer E, Vickers A, White AR: Acupuncture for tension-type headache. Cochrane Database Syst Rev 2009 CD007587.

58. Linde K, Allais G, Brinkhaus B, Manheimer E, Vickers A, White AR: Acupuncture for migraine prophylaxis. Cochrane Database Syst Rev 2009, CD001218.

59. Schneider A, Weiland C, Enck $P$, Joos S, Streitberger K, Maser-Gluth C, Zipfel S, Bagheri S, Herzog W, Friederich HC: Neuroendocrinological effects of acupuncture treatment in patients with irritable bowel syndrome. Complement Ther Med 2007, 15:255-263.

60. Fleckenstein J, Kramer S, Hoffrogge P, Thoma S, Lang PM, Lehmeyer L, Schober GM, Pfab F, Ring J, Weisenseel P, et al: Acupuncture in acute herpes zoster pain therapy (ACUZoster) - design and protocol of a randomised controlled trial. BMC Complement Altern Med 2009, 9:31.

\section{Pre-publication history}

The pre-publication history for this paper can be accessed here: http://www.biomedcentral.com/1472-6882/11/46/prepub

doi:10.1186/1472-6882-11-46

Cite this article as: Ursini et al:: Acupuncture for the treatment of severe acute pain in Herpes Zoster: results of a nested, open-label, randomized trial in the VZV Pain Study. BMC Complementary and Alternative Medicine 2011 11:46.

\section{Submit your next manuscript to BioMed Central and take full advantage of:}

- Convenient online submission

- Thorough peer review

- No space constraints or color figure charges

- Immediate publication on acceptance

- Inclusion in PubMed, CAS, Scopus and Google Scholar

- Research which is freely available for redistribution

Submit your manuscript at www.biomedcentral.com/submit
Ciomed Central 